OPEN ACCESS

Edited by: Carlos Tomaz,

Universidade Ceuma, Brazil

Reviewed by:

Vincenzo Micale,

Università degli Studi di Catania, Italy

Carmen Pedraza,

University of Málaga, Spain

*Correspondence:

Yvonne Bouter

yvonne.bouter@med.uni-

goettingen.de;

yvonne_bout@gmx.de

${ }^{\dagger}$ These authors have contributed equally to this work

Received: 15 February 2019 Accepted: 17 April 2019 Published: 07 May 2019

Citation:

Schleicher EM, Ott FW, Müller M, Silcher B, Sichler ME, Löw MJ, Wagner JM and Bouter Y (2019) Prolonged Cannabidiol Treatment Lacks on Detrimental

Effects on Memory, Motor

Performance and Anxiety in C57BL/6J Mice.

Front. Behav. Neurosci. 13:94 doi: 10.3389/fnbeh.2019.00094

\section{Prolonged Cannabidiol Treatment Lacks on Detrimental Effects on Memory, Motor Performance and Anxiety in C57BL/6J Mice}

\author{
Eva M. Schleicher ${ }^{\dagger}$, Frederik W. Ott ${ }^{\dagger}$, Melanie Müller, Barbara Silcher, Marius E. Sichler, \\ Maximilian J. Löw, Jannek M. Wagner and Yvonne Bouter*
}

Department of Psychiatry and Psychotherapy, Division of Molecular Psychiatry, University Medical Center Goettingen (UMG), Georg-August-University, Goettingen, Germany

The Cannabis plant contains more than 100 currently known phytocannabinoids. Regarding the rising consumption of the non-psychotropic phytocannabinoid cannabidiol (CBD) in people's everyday life (e.g., beauty products, food and beverages), the importance of studies on the influence of CBD on healthy humans and rodents is evident. Therefore, the behavioral profile of CBD was investigated with a battery of behavioral tests, including motor, anxiety, and memory tests after prolonged CBD treatment. Adult C57BI/6J wildtype (WT) mice were daily intraperitoneally injected with $20 \mathrm{mg} / \mathrm{kg}$ CBD for 6 weeks starting at two different points of ages ( 3 months and 5 months) to compare the influence of prolonged CBD treatment with a washout period (former group) to the effects of long term CBD treatment (current group). Our results show that CBD treatment does not influence motor performance on an accelerating Rotarod test, while it also results in a lower locomotor activity in the open field (OF). No influence of CBD on spatial learning and long term memory in the Morris Water Maze (MWM) was observed. Memory in the Novel Object Recognition test (NORT) was unaffected by CBD treatment. Two different anxiety tests revealed that CBD does not affect anxiety behavior in the Dark-Light Box (DLB) and OF test. Although, anxiety is altered by current CBD treatment in the Elevated Plus Maze (EPM). Moreover, CBDtreated $\mathrm{C} 57 \mathrm{BI} / 6 \mathrm{~J}$ mice showed an unaltered acoustic startle response (ASR) compared to vehicle-treated mice. However, current CBD treatment impairs prepulse inhibition (PPI), a test to analyze sensorimotor gating. Furthermore, prolonged CBD treatment did not affect the hippocampal neuron number. Our results demonstrate that prolonged CBD treatment has no negative effect on the behavior of adult C57BI/6J mice.

Keywords: cannabidiol, behavior, morris water maze, anxiety, cannabinoid system, cannabis

\section{INTRODUCTION}

Over the last years, there has been growing interest in the therapeutic potential of the phytocannabinoid cannabidiol (CBD) occurring naturally in the plant Cannabis sativa/indica, commonly known as marijuana. Several studies showed that CBD is involved, among others, in immunomodulatory, anti-inflammatory, antiemetic, anticonvulsant, anxiolytic, antipsychotic, 
muscle relaxant and neuroprotective processes (Atakan, 2012; Burstein, 2015; Watt and Karl, 2017). Interestingly, the interest in studying CBD initially came through its interaction with the probably most commonly recognized constituent of the cannabis plant, 9-Tetrahydrocannabinol (THC). CBD was first isolated by Adams et al. (1940) in 1940 and its structure was elucidated 23 years later (Cunha et al., 1980). The pharmacological mechanisms of THC are the most well understood among the more than 100 other currently known phytocannabinoids (Mechoulam et al., 2014). Whereas THC is dependent from CB1-, and CB2-receptor binding, the mechanism of action for CBD is still not fully understood (De Petrocellis and Di Marzo, 2010). There are several other receptors that appear to be involved in the therapeutic effect of CBD, such as TRPV1-, PPAR $\gamma$-, 5-HT1A-, and GPR55-Receptors (Zygmunt et al., 1999; Bouaboula et al., 2005; Russo et al., 2005; O’Sullivan, 2007; Ryberg et al., 2007).

Beneficial impacts of $\mathrm{CDB}$ on multiple diseases, such as multiple sclerosis (Mecha et al., 2013), brain ischemia (Schiavon et al., 2014; Mori et al., 2017) and epilepsy (Patra et al., 2019) have been shown in animal models.

Several studies support the beneficial effects of CBD for treating neuropsychiatric disorders, particularly affective disturbances as anxiety, depression and schizophrenia (Micale et al., 2013; Kucerova et al., 2014; Blessing et al., 2015). An anxiolytic effect has also been observed in healthy humans (Cunha et al., 1980). Recently, Stark et al. (2019) showed that early treatment with $\mathrm{CBD}$ can even prevent the appearance of schizophrenia-like deficits.

Surprisingly, few studies have examined the possible effects of prolonged CBD treatment on healthy mice. Studies of CBD effects have been mostly restricted to its acute effect and less is known about the efficiency after chronic CBD treatment. Therefore, the purpose of this study was to investigate the consequences of prolonged CBD treatment on the behavior of healthy C57BL/6J animals. In addition, we analyzed the effects of $\mathrm{CBD}$ on behavior after a washout period.

\section{MATERIALS AND METHODS}

\section{Animals and Drug Treatment}

C57BL/6J mice (Jackson Laboratories, Bar Harbor, ME, USA) were used in this study with an equal distribution of male and female mice. All animals were handled according to the guidelines of the Federation of European Laboratory Animal Science Association (FELASA) and approved by the "Lower Saxony State Office for Consumer Protection and Food Safety" (LAVES). Mice were kept in individually ventilated cages (IVC, $32 \times 16 \times 14 \mathrm{~cm}$; Tecniplast, Hohenpeißenberg, Germany) in groups up to five. Water and food were available ad libitum.

Powdered CBD (THC Pharm GmbH, Frankfurt/Main, Germany) was dissolved in equal amounts of $2.5 \mathrm{ml}$ Tween 80 (Carl Roth $\mathrm{GmbH}$, Karlsruhe, Germany) and $2.5 \mathrm{ml} \mathrm{100 \%}$ ethanol and diluted in $45 \mathrm{ml}$ of $0.9 \% \mathrm{NaCl}$ solution. A vehicle control treatment group was set up in the exact same way, with the exception of CBD. Mice were assigned to either CBD or vehicle-treated groups and treated daily with an intraperitoneal injection containing the injection volume of $10 \mathrm{ml} / \mathrm{kg}$ body weight for 6 weeks starting at the age of 3 months (in the following called "former") or 5 months (in the following called "current"; Figure 1). Mice were treated with $20 \mathrm{mg} / \mathrm{kg}$ body weight of CBD. Mice were weighed weekly and the injection volume was adjusted accordingly. In the current group, treatment continued during behavioral testing and lasted until the day of sacrifice. Behavioral testing started for all mice at the age of 6 months and mice were sacrificed with 26 weeks.

\section{Behavior Testing}

To detect possible behavioral and cognitive alterations due to prolonged $\mathrm{CBD}$ treatment, $\mathrm{C} 57 \mathrm{BL} / 6 \mathrm{~J}$ mice were tested in a battery of anxiety-, motor and memory-tests $(n=14-18)$. All mice were tested at the age of 6 months and testing lasted 18 days. Mice were sacrificed after the last day of testing.

Mice were kept on a $12 \mathrm{~h} / 12 \mathrm{~h}$ inverted light cycle. All behavior experiments were performed during the dark phase between 7 a.m. and 7 p.m. Ambient illumination was $624 \mathrm{~lx}$ in the light chamber and $3 \mathrm{~lx}$ in the dark chamber. Red light illumination was $173 \mathrm{~lx}$.

\section{Accelerating Rotarod}

To analyze motor performance and motor skill learning in CBD-treated mice the accelerating Rotarod test (RotaRod 3375-

5, TSE Systems GmbH, Bad Homburg, Germany) was used (Shiotsuki et al., 2010). C57BL/6J mice were placed face forwards

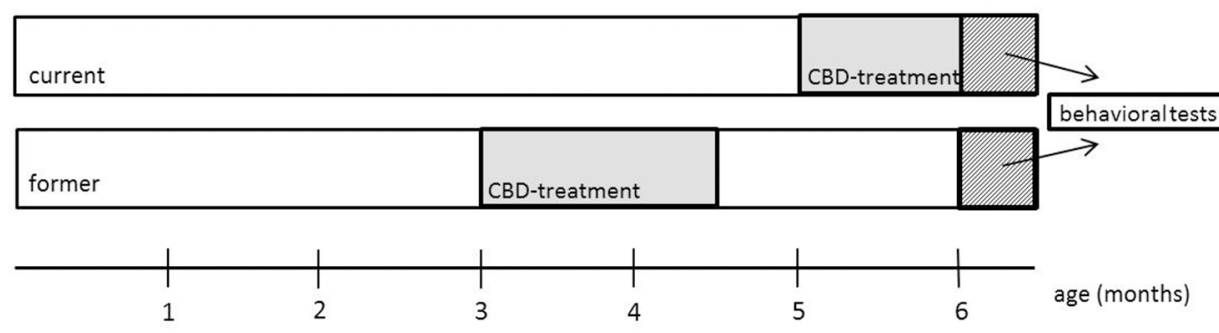

FIGURE 1 | Schematic overview of the experimental design. At 3 (former) and 5 months (current), mice were treated daily with cannabidiol (CBD) for 6 weeks. The test battery started at 6 months for both groups. The current group was still treated with CBD during behavioral testing. 
on the rod (Æ $30 \mathrm{~mm}, 60 \mathrm{~mm}$ width per mouse), suspended above a grid floor at a height of $14.7 \mathrm{~cm}$, high enough to create avoidance of falling and to prevent the mice deliberately jumping off the rod. Mice performed four trials per day on two consecutive days. To keep the mice focused on the task, the test was performed under red light. The rod accelerated from 4 to 40 revolutions per minute (rpm) over a time period of $300 \mathrm{~s}$ with an average inter-trial interval (ITI) of $15 \mathrm{~min}$ before the next trial started. For each trial, the time on the rod was recorded.

\section{Morris Water Maze}

The Morris Water Maze test (MWM; Morris, 1984) was used to evaluate spatial reference memory in CBD-treated C57BL/6J mice as previously described (Bouter et al., 2014). In brief, the test relies on spatial cues to locate a submerged hidden platform (10 cm diameter) in a circular pool filled with non-transparent tap water. For spatial coordination, the pool was divided into four virtual quadrants that were defined based on their spatial relationship to the platform: left, right, opposite and target quadrant, which contains the goal platform.

During the cued training the platform was marked with a triangular flag and both, platform and starting position were changed in the four trials per day with an ITI of $15 \mathrm{~min}$.

During acquisition training, spatial visual cues were fixed on the edge of the pool and the triangular flag was removed from the platform. This testing phase consisted of four trials per day over five consecutive days. Same trial procedures as for cued training were conducted.

The probe trial started $24 \mathrm{~h}$ after the last day of acquisition training to assess spatial reference memory at the end of the learning period. During the probe trial, the platform was removed from the pool and the mice were allowed to swim freely for $60 \mathrm{~s}$.

To record escape latency, swimming speed and quadrant preference, ANY-Maze video tracking software (Stoelting Co., Wood Dale, IL, USA) was used.

\section{Open Field and Novel Object Recognition}

The open field (OF) test was used to assess locomotor activity and exploratory behavior as described by Jawhar et al. (2012). During the OF test, mice were placed into a square box where they could freely explore the area for $5 \mathrm{~min}$. ANY-Maze video tracking software was used to record the percentage of time spent in the central part vs. total time and total distance traveled during a single 5-min trial.

Twenty-four hours after later, Novel Object Recognition Test (NORT) was performed in the same box, now containing two identical objects during the first testing day. The NORT is a widely used test to assess memory and preference for novelty in rodents (Antunes and Biala, 2012). Mice were allowed to explore freely for $5 \mathrm{~min}$. On day two of NORT, one of the objects was replaced by a novel object and the test time stayed the same. ANY-Maze video tracking software (Stoelting Co., Wood Dale, IL, USA) was used to record the distance traveled, percentage of time spent in the center and the exploration time of each object.
The percentage of exploration time for the novel object was calculated as follows:

$$
\text { Novel Object }[\%]=\left(\frac{\text { Novel Object }}{\text { Novel Object }+ \text { Familiar Object }} * 100\right)
$$

\section{Dark Light Box}

The Dark Light Box (DLB) was used to test for possible anxiolytic- or anxiogenic-like effects of prolonged CBD in C57BL/6J mice. This test is based on the innate aversion of rodents to brightly illuminated areas and on the spontaneous exploratory behavior of rodents in response to mild stressors, such as a novel environment and light (Bourin and Hascoët, 2003). The test was performed using a gray plastic box $(73 \mathrm{~cm} \times 25 \mathrm{~cm} \times 32 \mathrm{~cm})$, which was divided into two areas: a smaller dark area $(31 \mathrm{~cm} \times 25 \mathrm{~cm})$, covered by a black sheet made of plexiglass, and a larger light area $(42 \mathrm{~cm} \times 31 \mathrm{~cm})$, which was not covered. These two areas were separated by a gray wall with a small opening $(5 \mathrm{~cm} \times 5 \mathrm{~cm})$, allowing the mice to move freely from one compartment to the other. Each mouse was introduced into the light area facing the wall opposite of the small opening and was allowed to explore the space freely for $300 \mathrm{~s}$. ANY-Maze video tracking software (Stoelting Co., Wood Dale, IL, USA) was used to record the time spent in each compartment and the number of line crossings.

\section{Elevated Plus Maze}

The Elevated Plus Maze (EPM) test was used to assess anxietyrelated behavior in C57BL/6J mice as previously described (Jawhar et al., 2012). The apparatus with a shape of a "+" consisted of four arms and a central area raised $75 \mathrm{~cm}$ above a padded surface.

Mice were placed in the center facing one of the two likewise oppositely positioned open arms and were allowed to freely explore the maze for $300 \mathrm{~s}$. Distance traveled and the time spent in the open arms were recorded using ANY-Maze video tracking software (Stoelting Co., Wood Dale, IL, USA). Anxiety-like behavior can be measured by the time spent in the open arms as lower anxiety levels correspond to longer time spent in open arms (Karl et al., 2003).

\section{Prepulse Inhibition}

The prepulse inhibition (PPI) was used as a test for sensorimotor gating (Pouzet et al., 1999). Each mouse was placed individually in a small metal grid cage $(90 \mathrm{~mm} \times 40 \mathrm{~mm} \times 40 \mathrm{~mm})$ to restrict exploratory behavior and major movements. The cage was equipped with a movable platform floor attached to a sensor recording vertical movements of the floor. The cage was placed in a sound-attenuating isolation cabinet (TSE GmbH, Bad Homburg, Germany). Each experimental session started with a $3 \mathrm{~min}$ habituation period to $65 \mathrm{~dB}$ background white noise (continuous throughout the session) followed by a 2 -min baseline recording. Loudspeakers on both sides of the cage were used to induce startle reflexes by acoustic stimuli. A startle reaction to an acoustic stimulus including body muscle contractions and jumping causes movement of the platform. A transient force resulting from this movement was recorded during a time window of $100 \mathrm{~ms}$ beginning with the onset of the acoustic stimulus. 
Six pulse-alone trials using startle stimuli of $120 \mathrm{~dB}$ and $40 \mathrm{~ms}$ were applied after the baseline recording. PPI was tested applying the $120 \mathrm{~dB} 40 \mathrm{~ms}$ startle pulse alone or preceded by a prepulse $20 \mathrm{~ms}$ stimulus of 70-, 75- or $80 \mathrm{~dB}$. An interval of $100 \mathrm{~ms}$ with background noise was applied between each prepulse and pulse stimulus. Ten trials of startle response alone, no stimulus trials and pulse preceded by a 70-, 75- or $80 \mathrm{~dB}$ prepulse were applied in a pseudorandom order with ITIs from 8 to $22 \mathrm{~s}$. Maximum amplitudes for all types of trials were averaged for every mouse. PPIs at each sound level were calculated using the following formula:

$$
\begin{aligned}
& \text { Prepulse inhibition }[\%] \\
& =\left(1-\frac{\text { average startle amplitude after prepulse and pulse }}{\text { average startle amplitude after pulse alone }} * 100\right)
\end{aligned}
$$

\section{Quantification of Neuron Numbers Using Unbiased Stereology}

Stereological analysis was used to obtain the overall neuron number in the CA1 region of hippocampus as previously described (Bouter et al., 2013). Briefly, the hemisphere was cut into coronal sections of $30 \mu \mathrm{m}$ thickness, of which every tenth was systematically collected and stained with cresyl violet. The stereological analysis required a working station (Olympus BX51 with a motorized specimen stage for automatic sampling, StereoInvestigator 7; Microbrightfield, Williston, VT, USA). The CA1 region of sections from Bregma $-1.34 \mathrm{~mm}$ to $-3.80 \mathrm{~mm}$ were counted in, using a $100 \times$ oil lens $(\mathrm{NA}=1.35)$. Neurons were counted with the optical dissector method; consequently, the total number of neurons was estimated by the optical fractionator method using a $2 \mu \mathrm{m}$ top guard zone (West et al., 1991). The volume was calculated following Cavalieri's principle (Rosen and Harry, 1990).

\section{Statistical Analysis}

Differences between groups were tested with one-way and two-way analysis of variance (ANOVA) followed by Bonferroni multiple comparison or unpaired $t$-test as indicated. All data presented as mean \pm standard error of the mean (SEM). Significance levels are set as follows: ${ }^{* * * *} p<0.0001$; $^{* * *} p<0.001$; ${ }^{* *} p<0.01 ;{ }^{*} p<0.05$. All statistics were calculated using GraphPad Prism version 6.07 for Windows (GraphPad Software, San Diego, CA, USA).

\section{RESULTS}

\section{Cannabidiol Treatment Does Not Affect Motor Performance of C57BL/6J Mice}

No significant treatment effect was found in either former or current group (Figures 2A,C; two-way repeated measures ANOVA: treatment former: $F_{(1,27)}=1.792, p=0.1919$; treatment current: $\left.F_{(1,36)}=0.7475, p=0.393\right)$. Both vehicle and CBD-treated animals of the former and current treated groups showed a significant increase in motor performance over the eight trials (two-way repeated measures ANOVA: trials former:
$F_{(7,189)}=23.02, p<0.0001 ;$ trials current: $F_{(7,252)}=21.10$, $p<0.0001)$.

\section{Cannabidiol Treatment Has No Influence on Body Weight}

Former and current CBD-treated mice displayed similar weight compared to same-aged vehicle-treated mice over the 6 weeks of treatment (Figures 2B,D; two-way repeated measures ANOVA, treatment former: $F_{(1,27)}=1.045, p=0.32$; treatment current: $\left.F_{(1,36)}=0.627, p=0.434\right)$.

\section{Cannabidiol Treatment Does Not Alter Spatial Memory}

In the cued training period, for both, former and current groups, vehicle and $\mathrm{CBD}$-treated mice showed a significant decline in escape latency over time (Figures 3A,E; two-way repeated measures ANOVA, days former: $F_{(2,81)}=25.78, p<0.0001$; days current: $\left.F_{(2,107)}=85.89, p<0.0001\right)$. CBD-treated mice of the current group required significantly more time to find the platform only on day one than vehicle-treated mice (Figure 3E; two-way repeated measures ANOVA followed by Bonferroni multiple comparisons, treatment day $1: p<0.0001$ ). No overall differences in swimming speed could be detected between the age and treatment groups (data not shown; two-way repeated measures ANOVA, treatment). The cued training period revealed that all mice had an intact vision and the motoric abilities to swim.

Across the 5 days of acquisition training all animals, irrespective of treatment showed a significant decrease in the escape latencies (Figures 3B,F; two-way repeated measures ANOVA, days former: $F_{(4,134)}=17.49, p<0.0001$; days current: $\left.F_{(4,174)}=29.65, p<0.0001\right)$. During acquisition training no significant difference in swimming speed between the groups could be detected (data not shown; two-way repeated measures ANOVA, treatment).

\section{Cannabidiol Treatment Does Not Affect Spatial Reference Memory}

Twenty-four hours after the last acquisition trial, a probe trial was performed to assess spatial reference memory. Both the vehicle- and CBD-treated mice of the former group displayed a significantly higher preference for the target quadrant, as indicated by the relative time spent in the different quadrants of the pool (Figure 3C; one-way repeated measures ANOVA followed by Bonferroni multiple comparisons, former vehicle: $F_{(3,52)}=59.81, p<0.0001$; Bonferroni for target quadrant vs. left, vs. right and vs. opposite quadrant: $p<0.0001$; former CBD: $F_{(3,56)}=62.72, p<0.0001$, Bonferroni target quadrant vs. left, vs. right and vs. opposite quadrant: $p<0.0001)$. The swimming speed of the former group revealed no differences between the groups (Figure 3D; former: unpaired $t$-test, $F_{(14,13)}=1.29$, $p=0.367)$.

In the same way, mice of the current CBD treatment group showed a significant preference for the target quadrant (Figure 3G; one-way repeated measures ANOVA followed by Bonferroni multiple comparisons current vehicle: $F_{(3,72)}=25.73$, $p<0.0001$, Bonferroni for target quadrant vs. left, vs. right and 


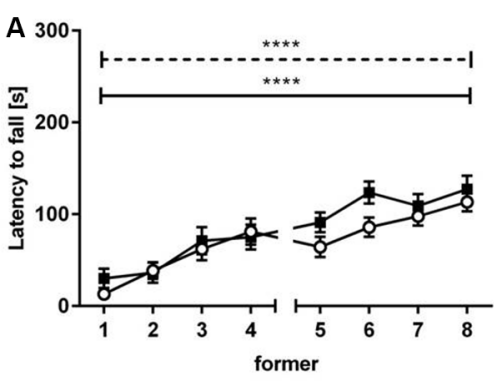

C

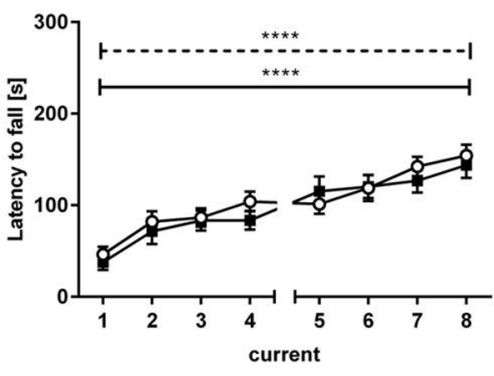

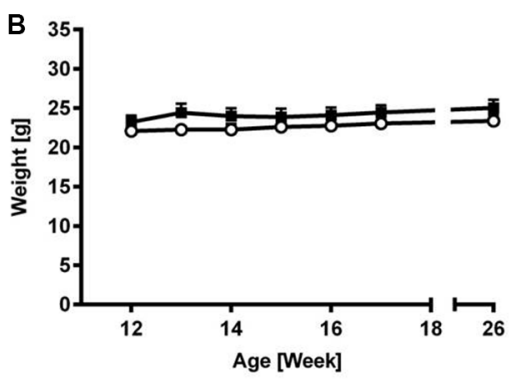

D

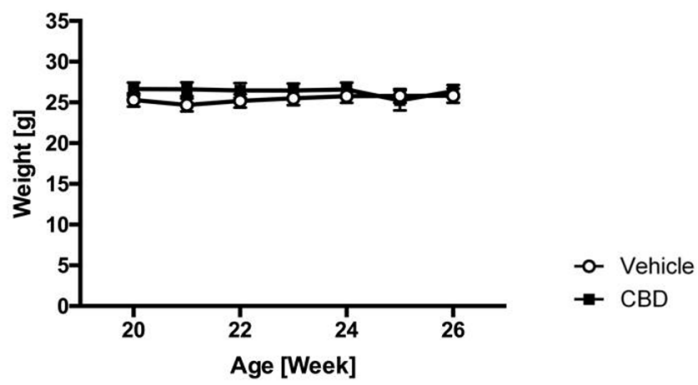

FIGURE 2 | CBD treatment does not influence motor performance of C57BL/6J mice. Latency to fall (A) and weight (B) for former CBD-treated C57BL/6J mice. No significant treatment effect between vehicle and CBD in the current treated group (C). Both groups showed an increased latency to fall over the training trials. No significant difference in weight in the current treatment group (D). $\mathrm{s}=$ seconds, $n=14-19,{ }^{* * * *} p<0.0001$; two-way repeated measures analysis of variance (ANOVA) followed by Bonferroni multiple comparisons. Data presented as mean $\pm \mathrm{SEM}$.

vs. opposite quadrant: $p<0.0001$; current CBD: $F_{(3,72)}=20.88$, $p<0.0001$, Bonferroni target quadrant vs. left, vs. right and vs. opposite quadrant: $p<0.0001 ;$ ). No difference in swimming speed was found among the current treatment groups (Figure 3H; current: unpaired $t$-test, $F_{(18,19)}=1.88, p=0.368$ ).

Our results show that prolonged CBD treatment does not impair spatial learning in $\mathrm{C} 57 \mathrm{BL} / 6 \mathrm{~J}$ mice compared to vehicletreated $\mathrm{C} 57 \mathrm{BL} / 6 \mathrm{~J}$ mice, irrespective of the treatment time.

\section{Cannabidiol Does Not Affect Memory in the Novel Object Recognition Test}

In the former treatment group, CBD-treated mice showed a clear preference for the novel object (Figure 3I; former CBD: paired $t$-test, $p=0.0002)$, which is seen in vehicle-treated mice, too (Figure 3I; former vehicle: paired $t$-test, $p=0.0263$ ). In the current treatment group, CBD-treated mice showed a trend towards a preference for the novel object (Figure 3J; current CBD: paired $t$-test, $p=0.0684$ ), whereas current vehicletreated mice did not (Figure 3J; current vehicle: paired $t$-test, $p=0.7866)$.

\section{Cannabidiol Does Not Affect Anxiety Behavior in the Dark Light Box}

In both, the former and current treatment group, CBD-treated mice did not explore the light box longer than the vehicle-treated mice (Figure 4A; former: unpaired $t$-tests,: $F_{(12,14)}=1.502$, $p=0.101$; Figure 4G; current: unpaired $t$-tests: $F_{(18,17)}=1.44$, $p=0.464)$. Regarding the former group, CBD-treated mice crossed the line slightly more often than vehicle mice (Figure 4B; former: unpaired $t$-test, $\left.F_{(13,13)}=2.03, p=0.672\right)$. In the current treatment group, there was no difference measured in the number of line crossings observed between CBD and vehicle-treated mice (Figure $\mathbf{4 H}$; current: unpaired $t$-test, $\left.F_{(18,17)}=2.47, p=0.095\right)$.

\section{Current Cannabidiol Treatment Alters} Anxiety Behavior in the Elevated Plus Maze Former CBD-treated animals did not show a significant difference in the amount of time spent in the open arms compared to vehicle-treated controls (Figure 4C; former: unpaired $t$-test, $\left.F_{(14,13)}=3.759 p=0.2856\right)$. In contrast, current CBD-treated mice showed a significant decrease in the time spent in the open arms vs. vehicle-treated control mice (Figure 4I; current: unpaired $t$-test, $\left.F_{(18,19)}=3.344, p=0.0134\right)$. The distance traveled was investigated to assess the confounding factor of movement. No significant difference in the distance traveled could be observed between the two different treatment groups, either with former or current treatment (Figure 4D; former: unpaired $t$-test $F_{(14,13)}=1.247, p=0.2642$; Figure 4J; current: unpaired $t$-test $\left.F_{(18,19)}=2.850, p=0.0969\right)$.

\section{Prolonged Cannabidiol Treatment Results in Lower Locomotor Activity in the Open Field}

No significant difference between former vehicle and CBD-treated groups in regard to the time spent in the center could be detected (Figure 4E; former: unpaired $t$-test, $\left.F_{(14,12)}=2.890, p=0.4435\right)$. However, there was a significant difference in the distance traveled for a former treated vehicle 


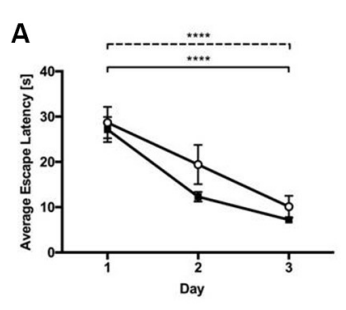

E
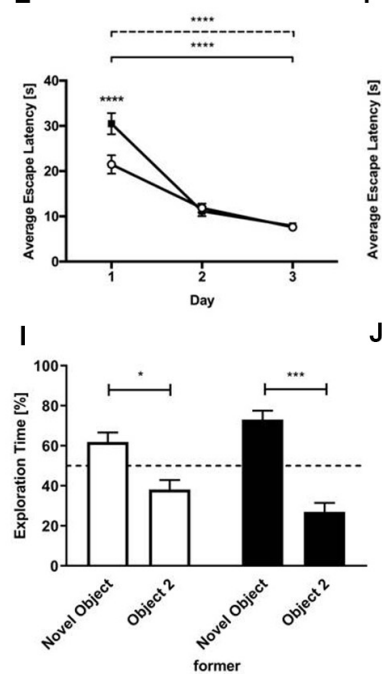

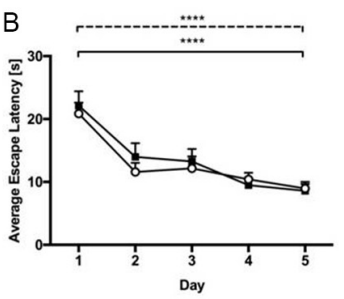

F

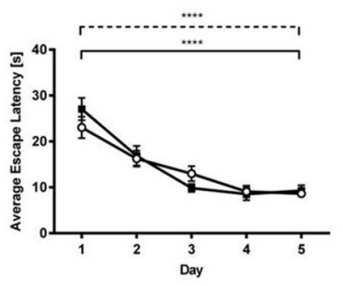

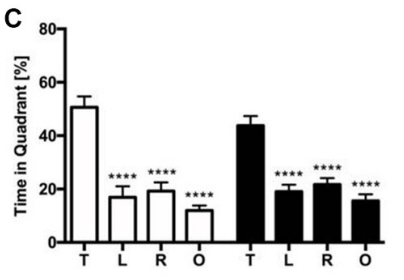

G

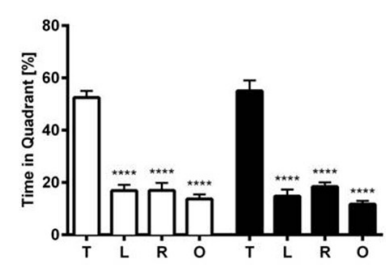

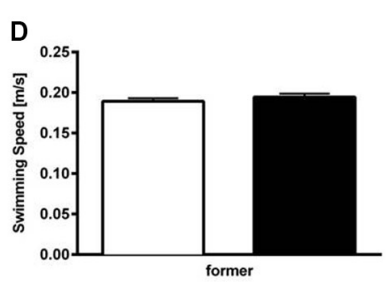

H

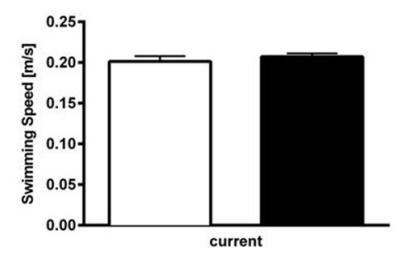

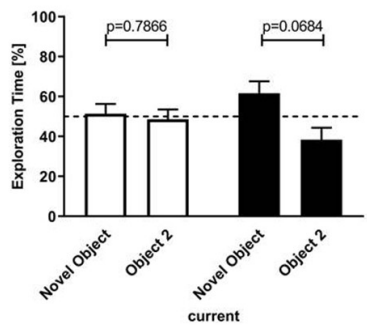

- Vehicle $\square$ Vehicle

- $\mathrm{CBD}$ CBD

FIGURE 3 | CBD treatment does not affect spatial learning and long term memory. CBD-treated and control mice of the former group displayed intact motor and visual performance in the Morris Water Maze (MWM; A). No impairment of spatial learning due to CBD treatment in acquisition training was seen in former treated mice (B). The probe trial revealed that the long term memory was not affected by prolonged CBD treatment in C57BL/6J mice of the former group as they spent significantly more time in the target quadrant compared to the other quadrants of the maze (C). The swimming speed during probe trial was not affected (D). Current treated mice proved visual and motor abilities to swim in cued training (E). Spatial learning was not altered as mice of the current group improved significantly during acquisition training (F). In probe trial, current CBD-treated mice and vehicle-control mice displayed a clear preference for the target quadrant (G). The swimming speed of the mice of the current group during probe trial did not differ significantly (H). Furthermore, CBD treatment did not affect memory in novel object recognition (NOR) in the former group (I). Whereas current CBD-treated mice (J) showed a trend towards novelty preference, former treated mice showed clear preferences for the novel object. Fifty percent chance level is indicated by a dashed line. Two-way (A,B,E,F) and one-way (C,G) ANOVA followed by Bonferroni multiple comparisons, unpaired $t$-test $\mathbf{( D , H )}$, paired $t$-test $(\mathbf{I}, \mathbf{J}) ; n=14-19,{ }^{* * * *} p<0.0001 ;{ }^{* * *} p<0.001 ;{ }^{*} p<0.05$. Data presented as mean \pm SEM.

vs. the CBD-treated group (Figure 4F; former: unpaired $t$-test, $\left.F_{(13,14)}=1.441, p=0.0081\right)$.

Similarly, current vehicle-treated mice traveled significantly more than CBD-treated mice (Figure $4 \mathrm{~L}$; current: unpaired $t$-test, $\left.F_{(19,18)}=3.861, p=0.0258\right)$, but did not spend significantly more time in the center than current vehicle-treated mice (Figure $4 \mathbf{K}$; current: unpaired $t$-test, $\left.F_{(19,18)}=1.235, p=0.4084\right)$.

\section{Cannabidiol Treatment Does Not Alter Acoustic Startle Response in C57BL/6J Mice}

The acoustic startle response (ASR) to the startle stimulus alone was measured in CBD- and vehicle-treated C57BL/6J animals (Figure 5). Former (Figure 5A) and current (Figure 5D) CBDtreated $\mathrm{C} 57 \mathrm{BL} / 6 \mathrm{~J}$ mice showed an unaltered startle response compared to same-aged vehicle C57BL/6J mice (former: unpaired t-test, $F_{(14,11)}=1.960, p=0.2672$; current: unpaired $t$-test, $\left.F_{(14,14)}=1.754, p=0.3048\right)$. Furthermore, the latency to startle was comparable between $\mathrm{CBD}$ and vehicle-treated animals (Figure 5B former: unpaired $t$-test, $F_{(14,11)}=2.124$, $p=0.8995$; Figure 5E current: unpaired $t$-test, $F_{(14,14)}=1.547$, $p=0.801)$.

\section{Current Cannabidiol Treatment Impairs Prepulse Inhibition in C57BL/6J Mice}

Current CBD wildtype (WT) treated mice displayed a significantly lower PPI compared to same-aged WT animals at $75 \mathrm{~dB}$ and $80 \mathrm{~dB}$ (Figure 5F; two-way repeated measures ANOVA: treatment current: $F_{(1,28)}=10.95, p=0.0026$; Bonferroni multiple comparison, vehicle vs. CBD: $75 \mathrm{~dB}$ $p<0.05$ and $80 \mathrm{~dB}: p<0.01)$. In contrast, former CBD treatment did not affect PPI (Figure 5C; two-way repeated measures ANOVA, treatment former: $\left.F_{(1,25)}=0.5182, p=0.4783\right)$.

\section{No Adverse Effect of CBD on Hippocampal Neuron Number}

Design-based stereological analysis revealed that the hippocampal neuron numbers of the CA1 region did not 

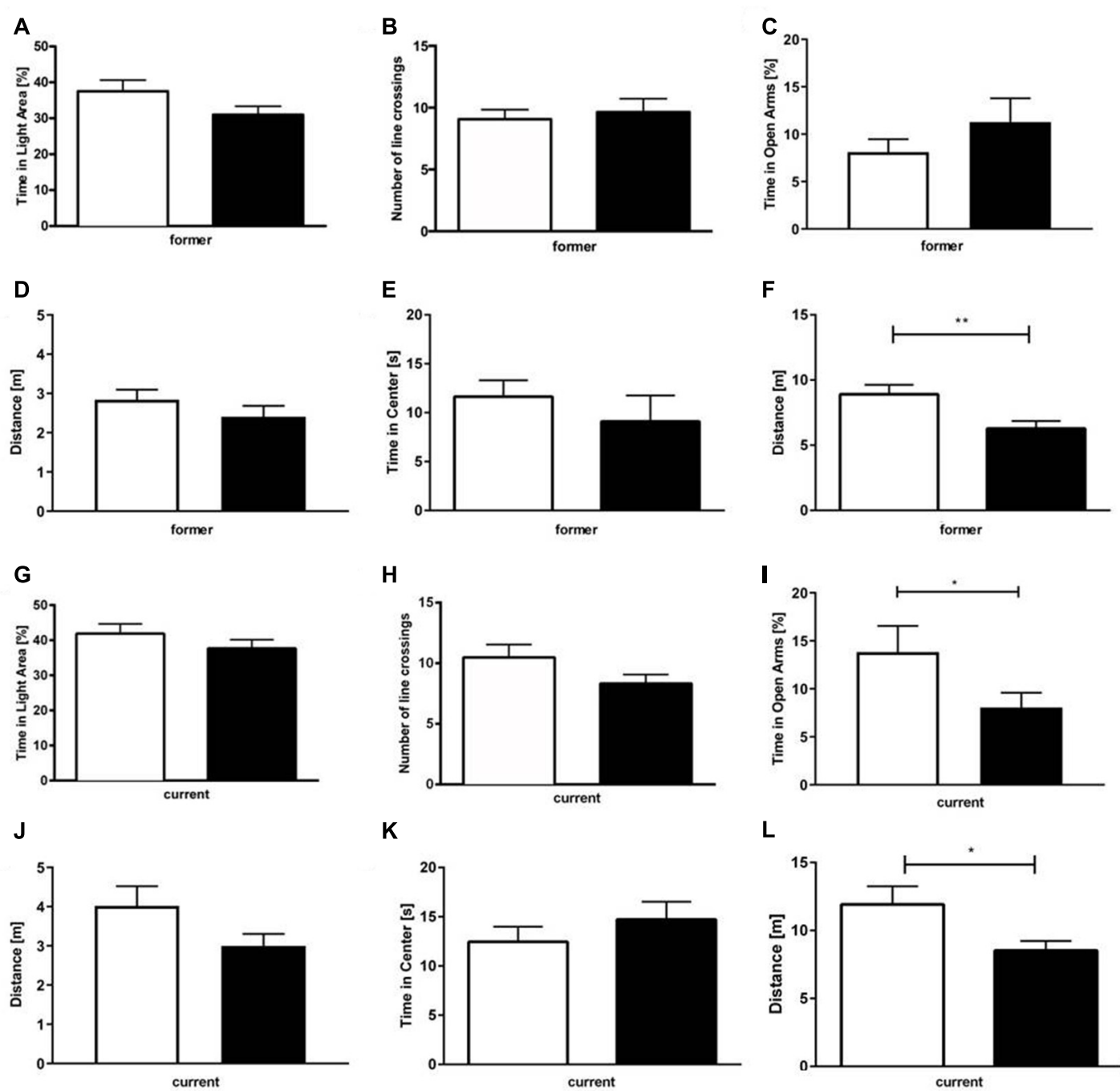

K

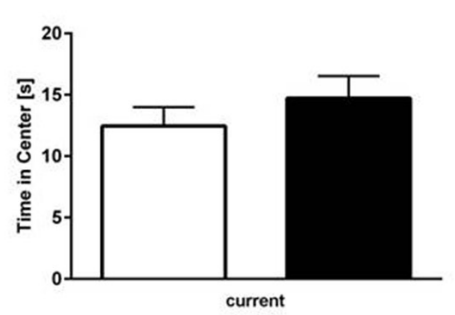

$\mathbf{L}$

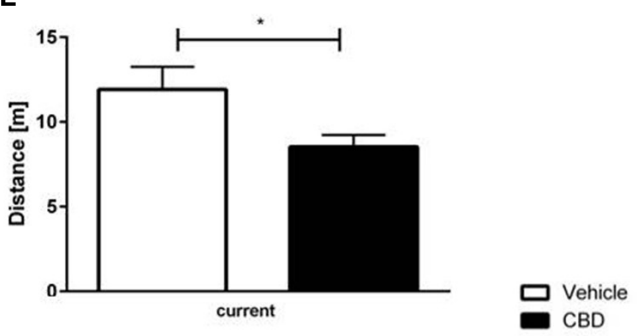

FIGURE 4 | Effects of prolonged CBD treatment on anxiety-related behavior. No significant difference in time spent in the light area in former CBD-treated mice (A). Number of line crossings as a confounding factor of mobility in the dark light box (DLB) did not significantly differ for the former treated group (B). Time spent in the open arms expressed as a percentage of total time spent in the maze (C) and traveled distance in the elevated plus maze (EPM) for former treated mice (D). In the open field (OF), there was no significant difference in time spent in the center of the box in former treatment group (E). Thus, a higher locomotor activity for vehicle-treated mice was found in the former CBD-treated mice (F). The time spent in the light area in current CBD-treated mice did not differ (G), as well as the number of line crossings in the DLB (H). Current CBD-treated mice showed a significant decrease in time spent in the open arms (I) but no difference in the distance traveled in the EPM (J). No significant difference between current CBD-treated mice and their vehicle-treated littermates in the time in the center (K), thus current CBD-treated mice traveled less distance in the OF (L). Unpaired $t$-test; $n=14-19,{ }^{* *} p<0.01 ;{ }^{*} p<0.05$. Data presented as mean \pm SEM.

significantly differ after former and current prolonged CBD treatment compared to the vehicle-treated mice (Figure 6A, one-way repeated measures ANOVA, $F_{(3,36)}=0.224$, $p=0.879$, former vehicle $=254,750 \pm 11,038$, former $\mathrm{CBD}=255,240 \pm 10,437$; current vehicle $=260,663 \pm 9,635$, current CBD $=247,134 \pm 14,129)$.

Likewise, no significant difference in volume of hippocampal CA1 region could be observed in the former or current group (Figure 6B; one-way repeated measures ANOVA, $F_{(3,36)}=1.198$, $p=0.324$; former: vehicle $=2.869 \mathrm{e}+008 \pm 1.806 \mathrm{e}+007, \mathrm{CBD}=$ $2.655 \mathrm{e}+008 \pm 1.005 \mathrm{e}+007$; current: vehicle $=2.965 \mathrm{e}+008 \pm$ $6.610 \mathrm{e}+006, \mathrm{CBD}=2.967 \mathrm{e}+008 \pm 1.634 \mathrm{e}+007)$.
The average number of sections counted was nine with a base of $196 \mu \mathrm{m}$ and an optical dissector height of $5 \mu \mathrm{m}$. The average number of sections counted was nine with a base of $196 \mu \mathrm{m}$ and an optical dissector height of $5 \mu \mathrm{m}$. The average predicted coefficient of error of the estimated total number of neurons was as followed: former vehicle: 0.056; former CBD: 0.056; current vehicle: 0.051; current CBD: 0.054 .

\section{DISCUSSION}

CBD has been discussed as a therapy for neurodegenerative diseases including multiple sclerosis as well as diseases known 


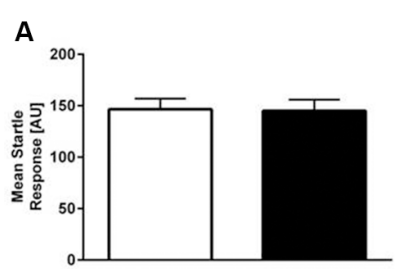

D

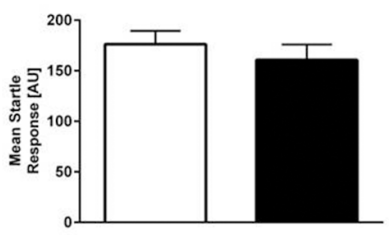

$\mathrm{B}$

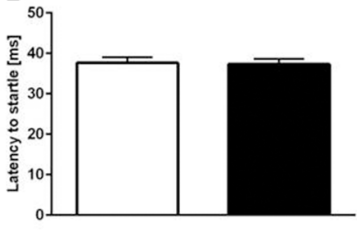

E

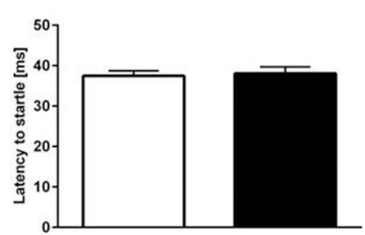

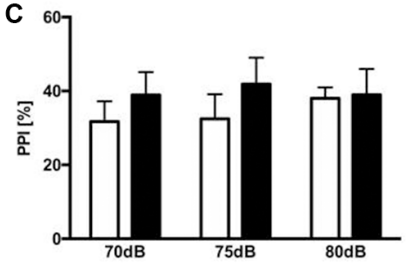

$\mathbf{F}$

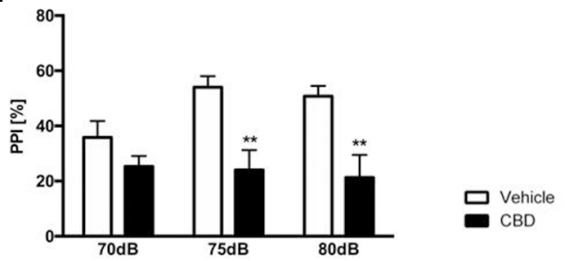

FIGURE 5 | Altered prepulse inhibition (PPI) in CBD-treated C57BL/6J mice. Former (A) and current (D) CBD-treated C57BL/6J mice showed an unaltered acoustic startle response (ASR) and latency to startle (B,E). PPI (PPI\%) was unaltered in former CBD-treated C57BL/6J (C). PPI was significantly altered in current treated CBD C57BL/6J mice at $75 \mathrm{~dB}$ and $80 \mathrm{~dB}(\mathbf{F})$. Two-way ANOVA, $n=12-15,{ }^{* *} p<0.01$. Data presented as mean $\pm \mathrm{SEM}$.
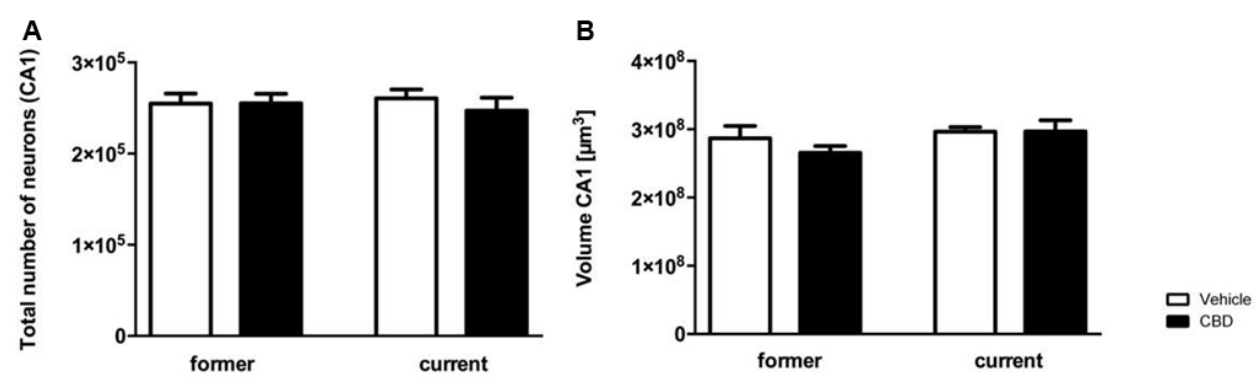

FIGURE 6 | Prolonged CBD treatment does not affect hippocampal neuron numbers and volumes in C57BL/6J mice. The CA1 region was counted from Bregma $-1.34 \mathrm{~mm}$ to $-3.80 \mathrm{~mm}$. Former as well as current CBD treatment had no influence on the total number of neurons in the CA1 region (A). The CA1 volumes of the $\mathrm{CBD}$ and vehicle-treated mice in the former and the current group did not differ significantly (B). One-way ANOVA (A,B); $n=9-11$. All data presented as mean \pm SEM.

for involving activation of the immune system and associated with oxidative stress (Iuvone et al., 2009; Krishnan et al., 2009; Scuderi et al., 2009; Booz, 2011). While most studies concentrate on THC, only a few studies investigate CBD treatment in healthy mice. However, there is evidence for many positive effects of prolonged CBD treatment on several brain-associated diseases like brain ischemia and epilepsy. Interestingly, positive effects of CBD treatment could be shown in mice with multiple sclerosis. CBD-treated mice with a dose of $5 \mathrm{mg} / \mathrm{kg}$ for 7-10 days reduced infiltration of leukocytes and the expression of cytokines (Mecha et al., 2013). Similarly, Patra et al. (2019) demonstrated a reduction of seizure burden as well as seizure severity in epilepsy models of rats and mice treated with CBD. In contrast to the probably most known constituent of the cannabis plant, $\mathrm{THC}$, the mechanism of action for CBD remains still unclear, mainly because it involves several pharmacological targets (De Petrocellis and Di Marzo, 2010). Regarding the rising amount of CBD-containing lifestyle products (e.g., cosmetics, energy bars, drinks) more and more people consume CBD in their everyday life. This emphasizes the importance of studies in healthy rodents and humans.
Our study examines the influence of prolonged $\mathrm{CBD}$ treatment on healthy adult $\mathrm{C} 57 \mathrm{BL} / 6 \mathrm{~J}$ mice and its consequences on behavior and hippocampal neuron numbers. Mice were divided into two treatment groups: a former treatment group and a current treatment group. The former treatment group received daily intraperitoneal injections of $20 \mathrm{mg} / \mathrm{kg}$ CBD-solution or vehicle-solution starting at the age of 3 months, while the current treatment group got the same treatment but started at the age of 5 months. Both groups started behavior testing at 6 months age. The aim of our study was to compare the influence of prolonged CBD treatment (current group) to the effects of prolonged CBD treatment with a washout period (former group) in adult mice.

It is described that there are sex differences in the modulation and expression of the endocannabinoid system. Cannabinoid exposure during adolescence has been shown to have long term consequences on brain and behavior (Andersen, 2003). Using cannabinoids during adolescence is more concerning because the endocannabinoid system is developed especially in this lifetime period and thus more vulnerable to exogenous insults as exposure of cannabinoids (Rice and Barone, 2000). It is known that gonadal hormones modulate the effects in cannabinoids in 
adult rodents, which were used in our study (Marusich et al., 2015). Several studies suggested that female rodents are more sensitive to the effects of THC than males (Craft et al., 2012; Marusich et al., 2014). Nevertheless, there is no evidence about the effects of CBD on the modulation of the endocannabinoid system. In our study, there was no gender difference regarding behavior (data not shown).

To evaluate the effect of chronic CBD treatment on reference and spatial memory, mice performed the MWM. No effect on spatial memory and long term memory could be observed. These findings correlate with the results of Fadda et al. (2004) who found no spatial learning impairments in CBD-treated rats in the MWM. Even at doses of up to $50 \mathrm{mg} / \mathrm{kg}$ CBD treatment had no effect on spatial working memory in these rats. Interestingly, research in a pharmacological mouse model of Alzheimer's disease revealed positive effects of $20 \mathrm{mg} / \mathrm{kg}$ CBD treatment in the MWM (Martín-Moreno et al., 2011).

Learning in the MWM is highly dependent on the hippocampus (D'Hooge and De Deyn, 2001), therefore, the effect of $\mathrm{CBD}$ treatment on the neuron number in the CA1-region of the hippocampus was analyzed. No significant difference in the number of neurons or the volume of the hippocampus was detected after CBD treatment. Interestingly, Schiavon et al. (2014) showed that CBD treatment reduced MWM deficits and hippocampal neurodegeneration in response to brain ischemia in mice in a dose-dependent way. Likewise, Mori et al. (2017) observed a protective effect of acute treatment with $10 \mathrm{mg} / \mathrm{kg}$ CBD 30 min before and 3, 24 and $48 \mathrm{~h}$ after operation induced brain ischemia on neurodegeneration in the hippocampus. In a recently performed MRI study with regular cannabis users there was, in accordance to our findings, no difference in total hippocampal volume observed after treatment with CBD, while left subicular complex volume significantly increased from baseline to post-treatment, indicating a restorative effect of $\mathrm{CBD}$ on the subicular and CA1 subfields in cannabis users (Beale et al., 2018).

Similar to our findings in the MWM, there is no significant difference for NORT, concerning non-spatial learning and memory in C57BL/6J mice after prolonged CBD treatment. Both vehicle- and CBD-treated groups of former treatment showed a clear preference to the novel object. Our results are in line with Fagherazzi et al. (2012) who showed that CBD (5 mg/kg or $10 \mathrm{mg} / \mathrm{kg}$ for 14 days) does not affect memory of male adult rats in the NORT, neither were general parameters of behavior such as exploratory activity, locomotion and anxiety affected. Interestingly, their study also provides evidence that CBD might rescue memory impairments associated with brain disorder. This is in line with the results of Pazos et al. (2012) after hypoxicischemic injury via electrocoagulation.

Although CBD-treated mice traveled less distance in the OF test, they still had a clear preference to the novel object which excludes the confounding factor of locomotion. This stands in contrast with the findings of Viudez-Martínez et al. (2018) that CBD does not alter motor behavior $12 \mathrm{~h}$ after its administration of $30 \mathrm{mg} / \mathrm{kg}$ for 6 days in the OF test.

While CDB-treated mice showed an altered locomotion their motor performance in the Rotarod test was intact.
Interestingly, Navarrete et al. (2018) observed a normalization of cannabis motoric withdrawal behavior signs in adult male C57BL/6 J mice. This effect is similar to the observation in healthy volunteers where $\mathrm{CBD}$ blocked the anxiety produced by THC (Zuardi et al., 1982).

Considering the significance of the endocannabinoid system for energy metabolism and feeding behavior, we examined the effects of prolonged CBD administration on body weight gain in C57BL/6J mice. In the current study, long term CBD administration did not affect the food uptake and appetite of mice as CBD-treated mice displayed similar weight compared to same-aged vehicle-treated mice. These results are in contrast with previous findings from Riedel and colleges who reported that acute CBD treatment $(10 \mathrm{mg} / \mathrm{kg}$, one injection) induced a small although non-significant reduction in food intake and weight gain (Riedel et al., 2009). Furthermore, CBD treatment was shown to decrease the weight gain in rats $(5 \mathrm{mg} / \mathrm{kg}$ for 14 days; Ignatowska-Jankowska et al., 2011). In adult male rats, oral administration of CBD $(4.4 \mathrm{mg} / \mathrm{kg})$ induced a significant reduction in total food intake over $4 \mathrm{~h}$ of test time (Farrimond et al., 2012). As we treated our mice for 42 days, these different findings may be the result of a habituation of the mice to the longer treatment time with $\mathrm{CBD}$. To our knowledge, there is no data about the influence of CBD for human weight and stimulation of appetite, which makes further studies much more necessary. In contrast, there is evidence that synthetic THC (Dronabinol) is associated with an increase in weight when compared to placebo in HIV positive humans (Whiting et al., 2015).

A significance towards less distance traveled by CBD-treated mice in former and current treatment group could be observed in the OF, whereas the number of line crossings as a comparable parameter for distance in the DLB differed between current and former treatment. The OF test is a common measure of exploratory behavior and general activity with less focus on anxiety than the EPM. Increased anxiety probably results in less locomotion and in the OF test in the preference to stay in the periphery of the box (Ennaceur, 2014). Regarding the results of both tests, an increased anxiety behavior could be discussed as it is significantly shown in the current CBD-treated group compared to their vehicle-treated littermates. A moderate anxiolytic-like effect in the OF test in C57BL/6J mice at $50 \mathrm{mg} / \mathrm{kg}$ dose of CBD daily treated for 3 weeks, was observed by Long et al. (2010), whereas even a dose of $1 \mathrm{mg} / \mathrm{kg}$ significantly increased the time spent in the light compartment. After observing effects in chronic CBD treatment, Long et al. (2010) investigated the acute behavioral effects of CBD $(1 \mathrm{mg} / \mathrm{kg} ; 50 \mathrm{mg} / \mathrm{kg})$ but no significant anxiolytic effects in the EPM could be found. In contrast to those findings, the current CBD-treated group in our study showed a significant decrease in the time spent in the open arms. Therefore, there is an anxiogenic-like effect of the current group in the EPM. Rats treated with lower doses of CBD $(2.5,5,10 \mathrm{mg} / \mathrm{kg})$ showed a significant increase in the entry ratio (open/total numbers of entries) which can be seen as an anxiolytic effect (Guimarães et al., 1990). Whereas a dose of $20 \mathrm{mg} / \mathrm{kg}$ had no effect compared to vehicle-treated male Wistar rats. This finding indicates that there is a limited range of 
anxiolytic doses and that the application and the following results are different in mice and rats. While CBD can be beneficial for treating anxiety, the beginning and the duration of the treatment is crucial and has to be considered and discussed in every treatment approach.

CBD treatment did not alter ASR in WT mice. Sensory gating describes the inhibition of a stimulus-related neuronal response if the stimulus is preceded by a subthreshold warning stimulus (Ally et al., 2006). Sensory gating can be measured using PPI, a method that can be studied with similar procedures in humans and rodents and reflects the ability to exclude sensory information from processing (Braff and Geyer, 1990). Current $\mathrm{CBD}$ altered sensorimotor gating, whereas former treated mice did not affect PPI. Our findings are well in line with the findings of Long et al. (2010) that there was no effect of CBD in ASR independent from the different acute treatment doses $(1,5,10$ or $50 \mathrm{mg} / \mathrm{kg})$, although acute and chronic $(1 \mathrm{mg} / \mathrm{kg})$ CBD treatment altered PPI. In Swiss mice, CBD treatment with $5 \mathrm{mg} / \mathrm{kg}$ had no effect on PPI but dose-dependently increased the startle response and reversed a MK-801-induced PPI deficit (Long et al., 2006).

Interestingly, altered sensory gating has been well documented in different psychiatric conditions including schizophrenia (Gjini et al., 2011; Rohleder et al., 2016). However, the influences of CBD on ASR and PPI in animal models of schizophrenia have been inconsistent. CBD treatment reversed PPI disruptive effects of MK-801 and amphetamine in mice, while CBD had no effect in rats treated with MK-801 (Gururajan et al., 2011; Gomes et al., 2014; Pedrazzi et al., 2015).

The effects of CBD on startle response and PPI seem to be highly species-, strain- and dose-dependent. However, the mechanism involved in CBD action on PPI is not yet understood, highlighting the need for more studies to clarify the relationship between CBD and PPI.

To summarize our findings, no side effects in C57BL/6J mice were evident regarding memory, motoric abilities or anxiety behavior after long term CBD treatment. Based on these results

\section{REFERENCES}

Adams, R., Hunt, M., and Clark, J. H. (1940). Structure of cannabidiol, a product isolated from the marihuana extract of minnesota wild hemp. I. J. Am. Chem. Soc. 62, 196-200. doi: 10.1021/ja01858a058

Ally, B. A., Jones, G. E., Cole, J. A., and Budson, A. E. (2006). Sensory gating in patients with Alzheimer's disease and their biological children. Am. J. Alzheimers Dis. Other Demen. 21, 439-447. doi: 10.1177/1533317506292282

Andersen, S. L. (2003). Trajectories of brain development: point of vulnerability or window of opportunity? Neurosci. Biobehav. Rev. 27, 3-18. doi: 10.1016/s01497634(03)00005-8

Antunes, M., and Biala, G. (2012). The novel object recognition memory: neurobiology, test procedure, and its modifications. Cogn. Process. 13, 93-110. doi: 10.1007/s10339-011-0430-z

Atakan, Z. (2012). Cannabis, a complex plant: different compounds and different effects on individuals. Ther. Adv. Psychopharmacol. 2, 241-254. doi: $10.1177 / 2045125312457586$

Beale, C., Broyd, S. J., Chye, Y., Suo, C., Schira, M., Galettis, P., et al. (2018). Prolonged cannabidiol treatment effects on hippocampal subfield volumes in current cannabis users. Cannabis Cannabinoid Res. 3, 94-107. doi: 10.1089/can. 2017.0047 it can be speculated that prolonged CBD treatment could be beneficial and safe for the treatment of a variety of conditions.

\section{DATA AVAILABILITY}

The datasets generated for this study are available on request to the corresponding author.

\section{ETHICS STATEMENT}

All animals were handled according to the guidelines of the Federation of European Laboratory Animal Science Association (FELASA) and approved by the "Lower Saxony State Office for Consumer Protection and Food Safety" (LAVES).

\section{AUTHOR CONTRIBUTIONS}

ES and FO performed experiments, analyzed data and wrote the manuscript. MS, JW, BS, MM and ML performed experiments. YB conceived and designed the project, performed experiments, analyzed data and wrote the manuscript. All authors contributed to revising the manuscript and approved the final version.

\section{FUNDING}

This work was supported by the German Research Foundation (CNMPB) to YB. This study was also supported by the JacobHenle-Program for Experimental Medicine of the University Medicine Goettingen to ML and JW. MS is supported by Helios Kliniken $\mathrm{GmbH}$. We acknowledge the support by the Open Access Publication Funds of the Göttingen University.

\section{ACKNOWLEDGMENTS}

We thank Prof. Thomas A. Bayer for fruitful discussions.

Blessing, E. M., Steenkamp, M. M., Manzanares, J., and Marmar, C. R. (2015) Cannabidiol as a potential treatment for anxiety disorders. Neurotherapeutics 12, 825-836. doi: 10.1007/s13311-015-0387-1

Booz, G. W. (2011). Cannabidiol as an emergent therapeutic strategy for lessening the impact of inflammation on oxidative stress. Free Radic. Biol. Med. 51, 1054-1061. doi: 10.1016/j.freeradbiomed.2011.01.007

Bouaboula, M., Hilairet, S., Marchand, J., Fajas, L., Le Fur, G., and Casellas, P. (2005). Anandamide induced PPAR $\gamma$ transcriptional activation and 3T3-L1 preadipocyte differentiation. Eur. J. Pharmacol. 517, 174-181. doi: 10.1016/j.ejphar.2005.05.032

Bourin, M., and Hascoët, M. (2003). The mouse light/dark box test. Eur. J. Pharmacol. 463, 55-65. doi: 10.1016/s0014-2999(03)01274-3

Bouter, Y., Dietrich, K., Wittnam, J. L., Rezaei-Ghaleh, N., Pillot, T., PapotCouturier, S., et al. (2013). N-truncated amyloid $\beta$ (A $\beta$ ) 4-42 forms stable aggregates and induces acute and long-lasting behavioral deficits. Acta Neuropathol. 126, 189-205. doi: 10.1007/s00401-013-1129-2

Bouter, Y., Kacprowski, T., Weissmann, R., Dietrich, K., Borgers, H., Brauß, A., et al. (2014). Deciphering the molecular profile of plaques, memory decline and neuron loss in two mouse models for Alzheimer's disease by deep sequencing. Front. Aging Neurosci. 6:75. doi: 10.3389/fnagi.2014. 00075 
Braff, D. L., and Geyer, M. A. (1990). Sensorimotor gating and schizophrenia. Human and animal model studies. Arch. Gen. Psychiatry 47, 181-188. doi: 10.1001/archpsyc. 1990.01810140081011

Burstein, S. (2015). Cannabidiol (CBD) and its analogs: a review of their effects on inflammation. Bioorg. Med. Chem. 23, 1377-1385. doi: 10.1016/j.bmc.2015. 01.059

Craft, R. M., Wakley, A. A., Tsutsui, K. T., and Laggart, J. D. (2012). Sex differences in cannabinoid 1 vs. cannabinoid 2 receptor-selective antagonism of antinociception produced by delta9-tetrahydrocannabinol and CP55,940 in the rat. J. Pharmacol. Exp. Ther. 340, 787-800. doi: 10.1124/jpet.111.188540

Cunha, J. M., Carlini, E. A., Pereira, A. E., Ramos, O. L., Pimentel, C., Gagliardi, R., et al. (1980). Chronic administration of cannabidiol to healthy volunteers and epileptic patients. Pharmacology 21, 175-185. doi: 10.1159/0001 37430

De Petrocellis, L., and Di Marzo, V. (2010). Non-CB1, non-CB2 receptors for endocannabinoids, plant cannabinoids, and synthetic cannabimimetics: focus on G-protein-coupled receptors and transient receptor potential channels. J. Neuroimmune Pharmacol. 5, 103-121. doi: 10.1007/s11481-009-9177-z

D'Hooge, R., and De Deyn, P. P. (2001). Applications of the Morris water maze in the study of learning and memory. Brain Res. Rev. 36, 60-90. doi: 10.1016/s0165-0173(01)00067-4

Ennaceur, A. (2014). Tests of unconditioned anxiety-pitfalls and disappointments. Physiol. Behav. 135, 55-71. doi: 10.1016/j.physbeh.2014. 05.032

Fadda, P., Robinson, L., Fratta, W., Pertwee, R. G., and Riedel, G. (2004). Differential effects of THC- or CBD-rich cannabis extracts on working memory in rats. Neuropharmacology 47, 1170-1179. doi: 10.1016/j.neuropharm.2004. 08.009

Fagherazzi, E. V., Garcia, V. A., Maurmann, N., Bervanger, T., Halmenschlager, L. H., Busato, S. B., et al. (2012). Memory-rescuing effects of cannabidiol in an animal model of cognitive impairment relevant to neurodegenerative disorders. Psychopharmacology 219, 1133-1140. doi: 10.1007/s00213-011-2449-3

Farrimond, J. A., Whalley, B. J., and Williams, C. M. (2012). Cannabinol and cannabidiol exert opposing effects on rat feeding patterns. Psychopharmacology 223, 117-129. doi: 10.1007/s00213-012-2697-x

Gjini, K., Burroughs, S., and Boutros, N. N. (2011). Relevance of attention in auditory sensory gating paradigms in schizophrenia A pilot study. J. Psychophysiol. 25, 60-66. doi: 10.1027/0269-8803/a000042

Gomes, F. V., Issy, A. C., Ferreira, F. R., Viveros, M. P., Del Bel, E. A., and Guimaraes, F. S. (2014). Cannabidiol attenuates sensorimotor gating disruption and molecular changes induced by chronic antagonism of NMDA receptors in mice. Int. J. Neuropsychopharmacol. 18:pyu041. doi: 10.1093/ijnp/ pyu041

Guimarães, F. S., Chiaretti, T. M., Graeff, F. G., and Zuardi, A. W. (1990). Antianxiety effect of cannabidiol in the elevated plus-maze. Psychopharmacology 100, 558-559. doi: 10.1007/bf02244012

Gururajan, A., Taylor, D. A., and Malone, D. T. (2011). Effect of cannabidiol in a MK-801-rodent model of aspects of schizophrenia. Behav. Brain Res. 222, 299-308. doi: 10.1016/j.bbr.2011.03.053

Ignatowska-Jankowska, B., Jankowski, M. M., and Swiergiel, A. H. (2011). Cannabidiol decreases body weight gain in rats: involvement of CB2 receptors. Neurosci. Lett. 490, 82-84. doi: 10.1016/j.neulet.2010.12.031

Iuvone, T., Esposito, G., De Filippis, D., Scuderi, C., and Steardo, L. (2009). Cannabidiol: a promising drug for neurodegenerative disorders? CNS Neurosci. Ther. 15, 65-75. doi: 10.1111/j.1755-5949.2008.00065.x

Jawhar, S., Trawicka, A., Jenneckens, C., Bayer, T. A., and Wirths, O. (2012). Motor deficits, neuron loss and reduced anxiety coinciding with axonal degeneration and intraneuronal A $\beta$ aggregation in the 5XFAD mouse model of Alzheimer's disease. Neurobiol. Aging 33, 196.e29-196.e40. doi: 10.1016/j.neurobiolaging. 2010.05.027

Karl, T., Pabst, R., and von Hörsten, S. (2003). Behavioral phenotyping of mice in pharmacological and toxicological research. Exp. Toxicol. Pathol. 55, 69-83. doi: 10.1078/0940-2993-00301

Krishnan, S., Cairns, R., and Howard, R. (2009). Cannabinoids for the treatment of dementia. Cochrane Database Syst. Rev. 2:CD007204. doi: 10.1002/14651858. cd007204.pub2
Kucerova, J., Tabiova, K., Drago, F., and Micale, V. (2014). Therapeutic potential of cannabinoids in schizophrenia. Recent Pat. CNS Drug Discov. 9, 13-25. doi: $10.2174 / 1574889809666140307115532$

Long, L. E., Malone, D. T., and Taylor, D. A. (2006). Cannabidiol reverses MK-801induced disruption of prepulse inhibition in mice. Neuropsychopharmacology 31, 795-803. doi: 10.1038/sj.npp.1300838

Long, L. E., Chesworth, R., Huang, X.-F., McGregor, I. S., Arnold, J. C., and Karl, T. (2010). A behavioural comparison of acute and chronic Delta9-tetrahydrocannabinol and cannabidiol in C57BL/6JArc mice. Int. J. Neuropsychopharmacol. 13, 861-876. doi: 10.1017/s1461145709990605

Martín-Moreno, A. M., Reigada, D., Ramírez, B. G., Mechoulam, R., Innamorato, N., Cuadrado, A., et al. (2011). Cannabidiol and other cannabinoids reduce microglial activation in vitro and in vivo: relevance to Alzheimer's disease. Mol. Pharmacol. 79, 964-973. doi: 10.1124/mol.111. 071290

Marusich, J. A., Craft, R. M., Lefever, T. W., and Wiley, J. L. (2015). The impact of gonadal hormones on cannabinoid dependence. Exp. Clin. Psychopharmacol. 23, 206-216. doi: 10.1037/pha0000027

Marusich, J. A., Lefever, T. W., Antonazzo, K. R., Craft, R. M., and Wiley, J. L. (2014). Evaluation of sex differences in cannabinoid dependence. Drug Alcohol Depend. 137, 20-28. doi: 10.1016/j.drugalcdep.2014.01.019

Mecha, M., Feliú, A., Iñigo, P. M., Mestre, L., Carrillo-Salinas, F. J., and Guaza, C. (2013). Cannabidiol provides long-lasting protection against the deleterious effects of inflammation in a viral model of multiple sclerosis: a role for A2A receptors. Neurobiol. Dis. 59, 141-150. doi: 10.1016/j.nbd.2013.06.016

Mechoulam, R., Hanuš, L. O., Pertwee, R., and Howlett, A. C. (2014). Early phytocannabinoid chemistry to endocannabinoids and beyond. Nat. Rev. Neurosci. 15, 757-764. doi: 10.1038/nrn3811

Micale, V., Di Marzo, V., Sulcova, A., Wotjak, C. T., and Drago, F. (2013). Endocannabinoid system and mood disorders: priming a target for new therapies. Pharmacol. Ther. 138, 18-37. doi: 10.1016/j.pharmthera.2012.12.002

Mori, M. A., Meyer, E., Soares, L. M., Milani, H., Guimarães, F. S., and de Oliveira, R. M. W. (2017). Cannabidiol reduces neuroinflammation and promotes neuroplasticity and functional recovery after brain ischemia. Prog. Neuropsychopharmacol. Biol. Psychiatry 75, 94-105. doi: 10.1016/j.pnpbp.2016. 11.005

Morris, R. (1984). Developments of a water-maze procedure for studying spatial learning in the rat. J. Neurosci. Methods 11, 47-60. doi: 10.1016/01650270(84)90007-4

Navarrete, F., Aracil-Fernández, A., and Manzanares, J. (2018). Cannabidiol regulates behavioural alterations and gene expression changes induced by spontaneous cannabinoid withdrawal. Br. J. Pharmacol. 175, 2676-2688. doi: $10.1111 / \mathrm{bph} .14226$

O'Sullivan, S. E. (2007). Cannabinoids go nuclear: evidence for activation of peroxisome proliferator-activated receptors. Br. J. Pharmacol. 152, 576-582. doi: 10.1038/sj.bjp.0707423

Patra, P. H., Barker-Haliski, M., White, H. S., Whalley, B. J., Glyn, S., Sandhu, H., et al. (2019). Cannabidiol reduces seizures and associated behavioral comorbidities in a range of animal seizure and epilepsy models. Epilepsia 60, 303-314. doi: 10.1111/epi.14629

Pazos, M. R., Cinquina, V., Gómez, A., Layunta, R., Santos, M., Fernández-Ruiz, J., et al. (2012). Cannabidiol administration after hypoxia-ischemia to newborn rats reduces long-term brain injury and restores neurobehavioral function. Neuropharmacology 63, 776-783. doi: 10.1016/j.neuropharm.2012.05.034

Pedrazzi, J. F., Issy, A. C., Gomes, F. V., Guimarães, F. S., and Del-Bel, E. A. (2015). Cannabidiol effects in the prepulse inhibition disruption induced by amphetamine. Psychopharmacology 232, 3057-3065. doi: 10.1007/s00213-0153945-7

Pouzet, B., Feldon, J., Veenman, C. L., Yee, B. K., Richmond, M., Rawlins, J. N. P., et al. (1999). The effects of hippocampal and fimbria-fornix lesions on prepulse inhibition. Behav. Neurosci. 113, 968-981. doi: 10.1037/0735-7044.113. 5.968

Rice, D., and Barone, S. Jr. (2000). Critical periods of vulnerability for the developing nervous system: evidence from humans and animal models. Environ. Health Perspect. 108, 511-533. doi: 10.2307/3454543

Riedel, G., Fadda, P., McKillop-Smith, S., Pertwee, R. G., Platt, B., and Robinson, L. (2009). Synthetic and plant-derived cannabinoid receptor antagonists show 
hypophagic properties in fasted and non-fasted mice. Br. J. Pharmacol. 156, 1154-1166. doi: 10.1111/j.1476-5381.2008.00107.x

Rohleder, C., Müller, J. K., Lange, B., and Leweke, F. M. (2016). Cannabidiol as a potential new type of an antipsychotic. A critical review of the evidence. Front. Pharmacol. 7:422. doi: 10.3389/fphar.2016.00422

Rosen, G. D., and Harry, J. D. (1990). Brain volume estimation from serial section measurements: a comparison of methodologies. J. Neurosci. Methods 35, 115-124. doi: 10.1016/0165-0270(90)90101-k

Russo, E. B., Burnett, A., Hall, B., and Parker, K. K. (2005). Agonistic properties of cannabidiol at 5-HT1a receptors. Neurochem. Res. 30, 1037-1043. doi: 10.1007/s11064-005-6978-1

Ryberg, E., Larsson, N., Sjögren, S., Hjorth, S., Hermansson, N.-O., Leonova, J., et al. (2007). The orphan receptor GPR55 is a novel cannabinoid receptor. $\mathrm{Br}$. J. Pharmacol. 152, 1092-1101. doi: 10.1038/sj.bjp.0707460

Schiavon, A. P., Soares, L. M., Bonato, J. M., Milani, H., Guimarães, F. S., and Weffort de Oliveira, R. M. (2014). Protective effects of cannabidiol against hippocampal cell death and cognitive impairment induced by bilateral common carotid artery occlusion in mice. Neurotox. Res. 26, 307-316. doi: 10.1007/s12640-014-9457-0

Scuderi, C., Filippis, D. D., Iuvone, T., Blasio, A., Steardo, A., and Esposito, G. (2009). Cannabidiol in medicine: a review of its therapeutic potential in CNS disorders. Phytother. Res. 23, 597-602. doi: 10.1002/ptr.2625

Shiotsuki, H., Yoshimi, K., Shimo, Y., Funayama, M., Takamatsu, Y., Ikeda, K., et al. (2010). A rotarod test for evaluation of motor skill learning. J. Neurosci. Methods 189, 180-185. doi: 10.1016/j.jneumeth.2010.03.026

Stark, T., Ruda-Kucerova, J., Iannotti, F. A., D’Addario, C., Di Marco, R., Pekarik, V., et al. (2019). Peripubertal cannabidiol treatment rescues behavioral and neurochemical abnormalities in the MAM model of schizophrenia. Neuropharmacology 146, 212-221. doi: 10.1016/j.neuropharm.2018.11.035

Viudez-Martínez, A., García-Gutiérrez, M. S., Medrano-Relinque, J., Navarrón, C. M., Navarrete, F., and Manzanares, J. (2018). Cannabidiol
Does Not Display Drug Abuse Potential in Mice Behavior. Available online at: https://www.nature.com/articles/s41401-018-0032-8. Accessed December 05, 2018.

Watt, G., and Karl, T. (2017). In vivo evidence for therapeutic properties of cannabidiol (CBD) for Alzheimer's disease. Front. Pharmacol. 8:20. doi: 10.3389/fphar.2017.00020

West, M. J., Slomianka, L., and Gundersen, H. J. (1991). Unbiased stereological estimation of the total number of neurons in thesubdivisions of the rat hippocampus using the optical fractionator. Anat. Rec. 231, 482-497. doi: 10.1002/ar.1092310411

Whiting, P. F., Wolff, R. F., Deshpande, S., Di Nisio, M., Duffy, S., Hernandez, A. V., et al. (2015). Cannabinoids for medical use: a systematic review and meta-analysis. JAMA 313, 2456-2473. doi: 10.1001/jama.2015.6358

Zuardi, A. W., Shirakawa, I., Finkelfarb, E., and Karniol, I. G. (1982). Action of cannabidiol on the anxiety and other effects produced by delta 9-THC in normal subjects. Psychopharmacology 76, 245-250. doi: 10.1007/bf00432554

Zygmunt, P. M., Petersson, J., Andersson, D. A., Chuang, H., Sørgård, M., Di Marzo, V., et al. (1999). Vanilloid receptors on sensory nerves mediate the vasodilator action of anandamide. Nature 400, 452-457. doi: 10.1038/22761

Conflict of Interest Statement: The authors declare that the research was conducted in the absence of any commercial or financial relationships that could be construed as a potential conflict of interest.

Copyright (C) 2019 Schleicher, Ott, Müller, Silcher, Sichler, Löw, Wagner and Bouter. This is an open-access article distributed under the terms of the Creative Commons Attribution License (CC BY). The use, distribution or reproduction in other forums is permitted, provided the original author(s) and the copyright owner(s) are credited and that the original publication in this journal is cited, in accordance with accepted academic practice. No use, distribution or reproduction is permitted which does not comply with these terms. 